Алехин Эдуард Владимирович

кандидат социологических наук, доцент кафедры государственного управления и социологии региона Пензенского государственного университета

Атяшкин Иван Александрович

студент Пензенского государственного университета

\section{ВОЗДЕЙСТВИЕ ОБЩЕСТВЕННОГО МНЕНИЯ НА СОЦИАЛЬНОЕ САМОЧУВСТВИЕ ГРАЖДАН (ПО МАТЕРИАЛАМ СОЦИОЛОГИЧЕСКОГО ИССЛЕДОВАНИЯ В ПЕНЗЕНСКОЙ ОБЛАСТИ)}

\section{Аннотация:}

В статье рассматриваются особенности формирования общественного мнения, факторы информационного воздействия на общественное мнение и социальное самочувствие граждан. Авторы акцентируют внимание на природе общественного мнения как социального явления. Отмечаются современные особенности формирования общественного мнения, обусловленные технологическим прорывом, коренным образом изменившим традиционное представление о передаче информации и давшим толчок развитию альтернативных каналов передачи информации - электронных СМИ и социальных сетей («ВКонтакте», Facebook, Instagram u др.), которые стали мошным инструментом воздействия на сознание человека. В статье перечислены основные факторы, влияющие на формирование общественного мнения, описывается корреляция общественного мнения и уровня самочувствия граждан; охарактеризован общероссийский провинциальный социальный фон. На основе опроса 3127 респондентов дается оценка социального самочувствия населения провинциальных городов Центральной России в зависимости от различных факторов (уровень определенности, уверенности в завтрашнем дне, материальная удовлетворенность, профессиональная деятельность, уровень образованности и др.). Сделан вывод о высокой степени воздействия общественного мнения на социальное самочувствие граждан.

Ключевые слова:

общественное мнение, провинция, город, социальное самочувствие, электронные СМИ, социальные cemu.

\section{Alekhin Eduard Vladimirovich}

PhD in Social Science, Associate Professor, Public Administration and Regional Sociology Department, Penza State University

Atyashkin Ivan Aleksandrovich

Student, Penza State University

THE IMPACT OF PUBLIC OPINION
ON THE SOCIAL WELL-BEING OF
CITIZENS (BASED ON
SOCIAL RESEARCH
IN PENZA REGION)

Summary:

The study discusses the aspects of forming public opinion, the information influencing factors in relation to public opinion and social well-being of citizens. The authors focus on the nature of public opinion as a social phenomenon. The research notes the modern features of shaping public opinion resulting from the technological advancement. The latter radically changed the traditional views on information transmission and contributed to the development of alternative infor mation channels such as e-media and social networking (Vkontakte, Facebook, Instagram) that provided a powerful tool for influencing the human consciousness. The paper lists the main factors influencing the formation of public opinion, correlates public opinion with the level of well-being of citizens and describes provincial social background in general. Based on a survey of 3,127 respondents, the authors assess the social well-being of the population depending on various factors (the levels of certainty, confidence in the future, financial satisfaction, professional activities and education). It is concluded that public opinion has a great impact on the social well-being of citizens.
Keywords: public opinion, province, city, social well-being, e-media, social networking.

Современное общество нельзя представить без перманентного потока информации. Технологии нашего времени коренным образом изменили традиционное представление о передаче информации различным адресатам. Появление новых технологий стало причиной развития альтернативных каналов передачи информации (мессенджера). В качестве основных каналов передачи информации можно выделить: традиционные СМИ (газеты, журналы, телевидение), электронные СМИ и социальные сети («ВКонтакте», Facebook, Instagram и др.). Сегодня мы можем с уверенностью говорить о том, что социальные сети стали мощным инструментом воздействия на сознание человека. Относительно новая ситуация, сложившаяся на медиарынке, становится предметом внимательного исследования специалистов по связям с общественностью. Принципиально новые каналы воздействия на общественное мнение вынуждают переосмысливать традиционные подходы в подаче информации. 
Общественное мнение является важным публичным инструментом, во многом определяющим решения органов государственной и муниципальной власти. Оно выступает предметом манипуляций, целью которых становится создание наиболее благоприятного информационного фона. Формированием общественного мнения занимаются общественные организации, органы государственной и муниципальной власти, бизнес-структуры [1].

Развитие каналов передачи информации способствует развитию инструментов и механизмов формирования общественного мнения. Большой практический опыт зарубежных и отечественных специалистов позволил сформировать значительный арсенал. Так что современные специалисты вооружены и методологиями, и инструментами, и механизмами эффективного формирования общественного мнения [2]. Многие эксперты убеждены, что общественное мнение в современных социальных процессах играет значимую, а порой и решающую роль.

Во многих источниках авторы характеризуют общественное мнение как «пятую власть» [3], при этом определяя чуть ли не главенствующую роль этому феномену в демократическом обществе. В связи с объективными изменениями во многих сферах жизнедеятельности человека произошла кардинальная перестройка социального мироустройства (бытия). С этим связано появление новой реальности, в которой можно увидеть как риски, так и возможности.

Осмысление этого тезиса наводит на следующую мысль: тот, кто сможет чувствовать тренды и даже их предугадывать, сможет без особого труда сбалансированно фрормировать общественное мнение. При этом для специалистов крайне очевидно, что поиск новых подходов к воздействию социальных институтов на общественное мнение - обязательное действие.

Уровень социального самочувствия граждан является хорошим маркером, отражающим здоровое общественное мнение. Социальное самочувствие жителей того или иного географического пространства представляет собой эмоциональную оценку населения окружающей социальной реальности.

Как известно, общественное мнение основывается на эмоционализации населения вокруг ключевых вопросов общественной жизни [4]. В связи с этим социальное самочувствие населения напрямую зависит от уровня эмоционализации информационного пространства.

В современной науке имеется более чем достаточное количество определений понятия «социальное самочувствие». В основном авторы опираются на понимание социального самочувствия как системы субъективных ощущений, свидетельствующих о той или иной степени физиологической и психологической комфортности [5]. Социальное самочувствие определяет в конечном счете индексы социального оптимизма, социальные страхи, уровень доверия населения к власти, уровень миграции и миграционных настроений.

Человеческая психология построена таким образом, что человек склонен менять свое мнение под воздействием какого-либо внешнего фактора. В качестве этого фактора может выступать мнение члена семьи, друга, одноклассника, соседа либо более авторитетного человека, обладающего «исчерпывающими» знаниями [6].

Информационное пространство, как уже было сказано ранее, существенным образом отличается от того, которое было некоторое время назад. Сегодня существует много разных информационных полей с абсолютно противоположными (полярными) информационными сообщениями. Полярная подача информации вызывает чувство растерянности, человек, не владеющий темой, не понимает, где истина, а где ложь. Если продолжительное время на него будет обрушиваться поток полярной информации, то в итоге у него сформируется усталость восприятия. Поэтому в качестве рекомендаций СМИ можно отметить фокусирование на наиболее важной теме и более детальное, предметное рассмотрение вопроса, чтобы дать возможность формирования здорового общественного мнения у этой категории граждан.

Одним из важных элементов социального самочувствия граждан является уровень доверия населения к власти. Здесь специалисты по связям с общественностью выступают в качестве главных заинтересованных лиц, потому что их действия при правильном сочетании инструментов и механизмов напрямую влияют на результат. Мало заниматься освещением мероприятий или решений того или иного органа власти. Важно выстраивать информационную кампанию, чтобы достичь желаемого воздействия на население. Для этого необходимо поддерживать интерес к обсуждаемой теме со стороны граждан.

В силу того, что большая часть людей узнает новости из социальных сетей, специалисты используют эти тренды с явным преимуществом. Во-первых, информация становится более адресной, что позволяет охватить разную целевую аудиторию и попасть в точку информационного восприятия и усвоения. Во-вторых, сокращается время передачи информации. В-третьих, возможны возвраты и повторы этой информации с большей результативностью, чем в традиционных СМИ. В-четвертых, возможно выстроить эффективную обратную связь, что позволяет грамотно аргументировать и оппонировать. 
Исследование социального самочувствия не сводится к получению информации о проблемах населения той или иной территории. Оно позволяет более объективно оценить социальную ситуацию в регионе в целом, выявить «болевые точки» социальной сферы, разработать меры, необходимые для ее устойчивого развития.

Люди, живущие в одно и то же время, казалось бы, имеют равные возможности по восприятию той или иной информации, но в действительности существуют характерные особенности, которые можно обозначить как «специфика территории» [7]. Под этим словосочетанием следует понимать специфические характеристики, свойственные жителям тех или иных населенных пунктов.

В целом можно сказать, что образ жизни, место работы, наличие хобби, интенсивность жизни, возможность посещения крупных мероприятий, путешествий по зарубежным странам влияют на представления человека о мире и, соответственно, формируют собственное мнение о происходящих событиях внутри страны [8]. Возможность видеть альтернативу выступает здесь главным инструментом формирования общественного мнения. Можно много о чем говорить красиво, показывать насыщенный информацией и яркими образами видеоряд, но, если у человека будет с чем сравнить, он обязательно сделает это.

Жизнь в провинциальном городе отличается от жизни в крупном мегаполисе. На сегодняшний день общероссийский провинциальный фон можно охарактеризовать следующими чертами: наличие одновременно в социальном пространстве города традиционных, индустриальных и постиндустриальных отношений с доминированием индустриальных и традиционных; широкая техническая модернизация на фоне отсутствия или слабого проявления социальных модернизаций; архаизация общественной жизни и общественных практик; из-за ползущей архаизации развитие типичной эмоции, определяющей социальное самочувствие населения - ощущение потерь; как следствие этого, наличие ряда институциональных ловушек; невыраженность архитектурного ландшафтта, диффференциальная урбанизация и дезурбанизация; неформальная занятость и «гаражная экономика»; доминирование семейных ценностей; общее отсутствие уникальности в городском социальном пространстве и городском социуме, унылое, подавленное эмоциональное состояние [9].

Общая оценка трендов в провинциальных городах позволяет изучить влияние их как на самочувствие жителей в целом, так и на формирование общественного мнения жителей относительно того же самочувствия, т. е. важно изучить, есть ли устойчивая корреляция между постепенным формированием общественного мнения и последующим изменением уровня самочувствия граждан на этом фоне.

Кроме того, анализ социального самочувствия российской провинции на примере Пензенской области поможет выявить базовые социальные настроения, свойственные большинству населенных пунктов нашей страны. Пензенский регион является типичным российским регионом, прошедшим первичную индустриализацию, совмещающую в себе признаки трех типов общества одновременно - традиционного, индустриального, постиндустриального.

Свои умозаключения мы представим, опираясь на большое исследование, которое проводилось ГАОУ ДПО «Институт регионального развития Пензенской области» по заказу правительства Пензенской области с 2014 по 2016 г. в городах Пензе, Никольске, Сердобске, Каменке, Нижнем Ломове, Заречном, Земетчино, Спасске. Выборка - 3127 респондентов. Методика исследования: массовый, экспертный опросы, наблюдения, контент-анализ местных СМИ.

Общий контекст социального самочувствия населения Пензенской области определяется ответами участников исследования на вопрос: «Насколько Вы удовлетворены своей жизнью в целом?». Полностью удовлетворены лишь 4,1\% опрошенных. Большинство респондентов $(36,7 \%)$ скорее удовлетворены, 27,5 \% затрудняются сказать точно, 23,5 \% не очень удовлетворены, а $8,2 \%$ совсем не удовлетворены своей жизнью.

Таким образом, 64,2 \% можно определить в общем как довольных своим социальным самочувствием. 27,5 \% неопределившихся респондентов можно считать в принципе удовлетворенными, но боящимися это признать из-за специфических региональных суеверий (боязнь сглазить) и специфического регионального менталитета (привычка жаловаться, чувствовать себя обделенными и прибедняться).

Тут же надо отметить, что контент-анализ местного информационного пространства на предмет позитивной и негативной информации (месседжей) дает примерно такие же показатели: $70 \%$ позитивной информации и 30 \% негативной. Среди позитивной информации можно выделить: строительство и открытие перинатального центра, реализацию проектов «Формирование комфортной городской среды» и «Безопасные и качественные дороги». Также все время появляются тематические сюжеты, например о повышении качества здравоохранения и развитии социального обеспечения жителей. Повышение информированности жителей о возможности обратиться в те или иные ведомства создает у граждан ощущение уверенности. 
Распределение мнений о жизненных перспективах позволяет говорить о преобладании ощущений неопределенности в отношении собственного будущего - 30,7 \%. Эта цифра, на наш взгляд, свидетельствует об общей атмосфере неопределенности и неуверенности в завтрашнем дне жителей региона. Кроме того, почти треть респондентов составляли студенты учреждений ВО и СПО, представляющие молодое поколение Пензенского региона. Как известно, молодежи большинства развитых стран характерно чувство пессимизма и неуверенности. При сопоставлении долей оптимистов (кто скорее уверен (29,7\%) и вполне уверен $(8,9 \%)$ в своем будущем) и пессимистов (кто скорее неуверен (17,8 \%) и совершенно неуверен $(12,9 \%)$ в своем будущем) прослеживается незначительное преобладание первых (38,6 и 30,7 \% соответственно).

В ходе исследования была выявлена следующая тенденция: уровень социального самочувствия напрямую зависит от оценки респондентами своего материального положения. Чем выше материальное положение респондентов, тем выше уровень их социального самочувствия. Что касается уровня материального положения, то информационные сюжеты в СМИ о качестве материального положения тоже выходят регулярно. В основном они носят оценочный характер. Средняя заработная плата по региону достигла среднего уровня, но ей есть куда расти.

Кроме того, уровень социального самочувствия напрямую зависит от удовлетворенности респондентов условиями самореализации. Чем выше удовлетворенность респондентов условиями самореализации, тем выше уровень их социального самочувствия.

Оценка уровня социального самочувствия у женщин немного ниже, чем у мужчин, поскольку они, как правило, чаще имеют более низкий экономический и профессиональный статус, а также чаще сталкиваются с проблемами в сфере образования, здравоохранения, ЖКХ. Уровень социального самочувствия самый высокий в возрастной группе от 26 до 30 лет (69,2 \%), несколько ниже - в группе от 41 до 45 лет (50 \%), самый низкий - в возрастных группах от 56 до 60 лет (0 \%) и 61 года и старше $(12,5 \%)$.

В ходе проведенного исследования были получены данные, характеризующие актуальное состояние социального самочувствия опрошенных жителей Пензенской области в целом и в различных группах населения. В целом по выборке социальное самочувствие на момент опроса стало в той или иной мере лучше у 14,2 \% респондентов. В то же время 45,4 \% опрошенных отмечают его ухудшение и 40,4 \% считают, что по сравнению с прошлым годом в их жизни и жизни их семьи ничего не изменилось.

В зависимости от профессиональной деятельности отмечаются различия в характеристике социального самочувствия. Установлено, что среди пенсионеров, руководителей организаций и учащихся техникумов все респонденты отмечают в той или иной мере ухудшение своего социального самочувствия (77,8, 100 и 33,3 \% соответственно). Число рабочих и руководителей отделов и подразделений, отмечающих улучшение социального самочувствия, значительно превосходит процент респондентов, отмечающих его ухудшение (50 и 11,1 \%; 57,1 и 14,3 \% соответственно). Практически в равной мере отмечают и улучшение, и ухудшение социального самочувствия специалисты (22,2 и 27,8 \% соответственно), и они же наиболее высоко его оценивают. При этом характерно, что среди руководителей организаций наиболее высок процент респондентов, сравнительно с перечисленными группами, считающих, что их социальное самочувствие в той или иной степени ухудшилось (100\%).

В зависимости от уровня образования также отмечаются различия в характеристике социального самочувствия. Наиболее высоко оценивают свое социальное самочувствие респонденты, имеющие среднее профессиональное образование (20,8 \%). Процент респондентов, имеющих основное общее и высшее образование, отмечающих ухудшение социального самочувствия, значительно превосходит процент респондентов, отмечающих его улучшение (66,6 и 16,7 \%; 50 и 13 \% соответственно). При этом характерно, что среди респондентов с наличием ученой степени и ученого звания наиболее высок процент, сравнительно с перечисленными группами, считающих, что их социальное самочувствие в той или иной степени ухудшилось (100 и 100 \% соответственно).

Таким образом, анализ результатов исследования показал, что уровень удовлетворенности населения жизнью в Пензенском регионе можно характеризовать как пограничный и противоречивый, размытый, эмоционально неустойчивый, пассивный. На специфику оценки своего социального самочувствия влияют общая неопределенность в социальной, политической, экономической сферах, которая снижает уровень позитивных оценок, формирует чувство неуверенности в завтрашнем дне и общий пессимистический фон [10].

Общественное мнение в целом может формировать уровень социального самочувствия граждан. Информационная политика может стать основой при создании определенного социально-психологического состояния населения [11].

Как сказал доктор фрилософских наук, профессор Н. Мансуров: «Таким образом, общественное мнение - это та реальность, вне которой нет ни существования, ни развития общества, состоящего из общностей». 
Проанализировав результаты, полученные в ходе проведения социологического опроса, можно сделать вывод, что уровень воздействия общественного мнения на социальное самочувствие граждан высокий.

\section{Ссылки:}

1. Герасимова Г.И. Связи с общественностью как социальный механизм взаимодействия власти и общества // Власть. 2008. № 9. С. 33-36.

2. Розанова Н.Н. Модели информационного воздействия в формировании имиджа и репутации российской власти // Век качества. 2009. № 5. С. 21-23.

3. Бануляк Н.А. Службы по связям с общественностью в органах государственной власти // Социология власти. 2011. № 5. C. $165-171$.

4. Коданина А.Л. Связи с общественностью в органах государственной власти и управления // Там же. 2010. № 2. C. 218-227.

5. Robinson P. The Policy-Media Interaction Model: Measuring Media Power During Humanitarian Crisis // Journal of Peace Research. 2000. Vol. 37, no. 5. https://doi.org/10.1177/0022343300037005006.

6. Герасимова Г.И. Технологии связей с общественностью в структуре взаимодействия субъектов общественных отношений // Известия вузов. Поволжский регион. Общественные науки. 2011. № 3. С. 67-73.

7. Кошман М.В. Специфика связей с общественностью как социальной коммуникации в современном российском обществе // Вестник ДГТУ. 2009. № 3. С. 28-33.

8. Социальное самочувствие населения в условиях рефоорм: региональный аспект / ред. М.К. Горшков. М. ; СПб., 2011.

9. Герасимова Г.И. Указ. соч.

10. Синяева И.М., Маслова В.М., Синяев В.В. Сфера PR в маркетинге : учеб. пособие. М., 2007. 383 с.

11. Мухортова А.В., Федорова А.В. Повышение эффективности связей с общественностью в государственных структурах // Инновационная наука. 2015. № 12-3. С. 242-245.

\section{References:}

Banulyak, NA 2011, 'Public Relations Services in Public Authorities', Sotsiologiya vlasti, no. 5, pp. 165-171, (in Russian). Gerasimova, GI 2008, 'Public Relations as a Social Mechanism of Interaction between Power and Society', Vlast', no. 9, pp. 33-36, (in Russian).

Gerasimova, GI 2011, 'PR Technologies in the Interaction Structure of Social Relations Subjects', Izvestiya vuzov. Povolzhskiy region. Obshchestvennyye nauki, no. 3, pp. 67-73, (in Russian).

Gorshkov, MK (ed.) 2011, Social Well-Being of the Population in the Context of Reforms: a Regional Aspect, Moscow, St. Petersburg, (in Russian)

Kodanina, AL 2010, 'Public Relations in Public Authorities and Government', Sotsiologiya vlasti, no. 2, pp. 218-227, (in Russian).

Koshman, MV 2009, 'The Specific Nature of Public Relations as Social Communication in the Modern Russian Society', Vestnik DGTU, no. 3, pp. 28-33, (in Russian).

Mukhortova, AV \& Fedorova, AV 2015, 'Increased Efficiency of Public Relations in the State Structures', Innovatsionnaya nauka, no. 12-3, pp. 242-245, (in Russian).

Robinson, P 2000, 'The Policy-Media Interaction Model: Measuring Media Power During Humanitarian Crisis', Journal of Peace Research, vol. 37 (5). https://doi.org/10.1177/0022343300037005006.

Rozanova, NN 2009, 'Models of Information Impact in Forming the Image and Reputation of the Russian Authorities', Vek kachestva, no. 5, pp. 21-23, (in Russian).

Sinyaeva, IM, Maslova, VM, Sinyaev, VV 2007, PR in Marketing, textbook, Moscow, 383 p., (in Russian). 